\title{
Macroscopic characteristics facilitate identification of common Antarctic glass sponges (Porifera, Hexactinellida, Rossellidae)
}

\author{
Luisa Federwisch ${ }^{1,2} \circledast$ Dorte Janussen $^{3} \cdot$ Claudio Richter $^{1,2}$
}

Received: 21 June 2019 / Revised: 8 December 2019 / Accepted: 10 December 2019 / Published online: 21 January 2020

(c) The Author(s) 2020

\begin{abstract}
Glass sponges (Porifera, Hexactinellida) are conspicuous habitat-forming members of many Antarctic shelf communities. Despite their ecological importance, in-situ species identification remains problematic as it is traditionally based on microscopic analysis of spicules. External morphological features, in contrast, have largely been disregarded, so that different species have been mislabeled or lumped together when their identification was based on image material. In this paper, we provide a straight-forward guideline for in-situ identification of the most common rossellid sponges of the Antarctic shelf based on macroscopic characteristics. To determine diagnostic macroscopic characteristics of Anoxycalyx (Scolymastra) joubini and eight Rossella species, we combined examination of trawl-collected specimens, previous species descriptions and in-situ image material from the eastern Weddell Sea. Our study revealed that the smooth-walled species A. joubini, $R$. nuda and $R$. vanhoeffeni, previously often mixed up, can be distinguished by the form of their basal spicule tuft, their surface structure and their overall body form. The previously synonymized species $R$. racovitzae and $R$. podagrosa can be distinguished by their markedly different habitus. Based on our results, the so-called ' $R$. racovitzae budding type' in fact refers to $R$. podagrosa which occurs regularly in the eastern Weddell Sea. The species $R$. villosa, $R$. levis, $R$. fibulata and $R$. antarctica can be distinguished by the appearance of their conules, protruding spicules and overall body form. We conclude that macroscopic characteristics are helpful means for identification of Antarctic rossellid sponge species. This approach enables species-specific quantitative studies of Antarctic glass sponge grounds based on increasingly used non-invasive imaging technology.
\end{abstract}

Keywords Anoxycalyx joubini $\cdot$ Rossella $\cdot$ Weddell Sea $\cdot$ Species identification $\cdot$ Image analysis

\section{Introduction}

Glass sponges (Porifera, Hexactinellida) are conspicuous members of benthic communities in Antarctic shelf regions. Predominant among them is the family Rossellidae

Electronic supplementary material The online version of this article (https://doi.org/10.1007/s00300-019-02612-2) contains supplementary material, which is available to authorized users.

Luisa Federwisch

luisa.federwisch@awi.de

1 Alfred-Wegener-Institut Helmholtz-Zentrum für Polar- und Meeresforschung, Am Handelshafen 12, 27570 Bremerhaven, Germany

2 Faculty 2 (Biology/Chemistry), University of Bremen, 28334 Bremen, Germany

3 Forschungsinstitut und Naturmuseum Senckenberg, Senckenberganlage 25, 60325 Frankfurt am Main, Germany
(Janussen and Downey 2014). These sponges can form vast sponge grounds (Maldonado et al. 2016) and are major contributors to benthic biomass (Gerdes et al. 1992). As they grow to considerable sizes (Barthel and Tendal 1994), they are important structuring elements of Antarctic shelf communities (Barthel 1992; Barthel and Gutt 1992; Gutt et al. 2013, 2016; Kersken et al. 2016) and provide habitat for a diverse associated fauna (Kunzmann 1996; Barthel 1997; Kersken et al. 2014). In contrast to long-held views of slow growth (e.g., Barthel and Tendal 1994; Gatti 2002), rossellid sponge populations respond dynamically to environmental changes like shifts in ice cover and productivity (Fillinger et al. 2013; Dayton et al. 2013, 2016). Further impacts of climate-induced changes can be expected in the future, but as different species show different life history patterns (Dayton et al. 2013), general trends are hard to foresee.

Despite their well-established ecological importance, species identification of the most common glass sponges of the 
Antarctic shelf, Rossella spp. and Anoxycalyx (Scolymastra) joubini, remains problematic. It is traditionally based on the morphology and architecture of microscopic skeletal elements-spicules - which are isolated by elaborate preparation techniques (e.g., Boury-Esnault and Rützler 1997). However, modern quantitative studies in ecology, biodiversity or biogeography are increasingly based on non-invasive techniques, such as Remotely Operated Vehicles (ROVs) or towed camera systems (Mallet and Pelletier 2014; Durden et al. 2016) which provide no material for spicule analysis. Consequently, researchers have to rely on macroscopic characteristics to identify sponge species on image material.

Unfortunately, the external morphological features have traditionally been dismissed as non-conservative and unsuitable for characterizing species and have thus not been well described. Some of the early species descriptions are based on tiny individuals (e.g., $R$. racovitzae, Topsent 1901) or fragments only (e.g., R. fibulata, Schulze and Kirkpatrick 1910). Furthermore, most descriptions are based on material collected by trawls (e.g., Barthel and Tendal 1994; Göcke and Janussen 2013) which sometimes is difficult to relate to the appearance of species in situ. Even recent studies largely focus on the spicules and provide only limited information on macroscopic characteristics and few photographs of the species' habitus (e.g., Göcke and Janussen 2013).

Besides lacking clarity or comprehensiveness in species descriptions, the complicated taxonomic history of the genus Rossella adds further problems. About 25 species and varieties have been described (Reiswig 1990), followed by numerous synonymizations and revisions (for a summary see Göcke et al. 2015). In the latest taxonomic revision of Antarctic Rossellidae, Barthel and Tendal (1994) recognized seven species of Rossella: $R$. antarctica, $R$. fibulata, $R$. levis, $R$. nuda, $R$. racovitzae, $R$. vanhoeffeni and $R$. villosa. Although they only partly incorporated external morphological characteristics, their concept is the most applicable to date and widely used (e.g., Göcke and Janussen 2011; Göcke and Janussen 2013; Fillinger et al. 2013; Dayton et al. 2016; Kersken et al. 2016).

However, the morphological variability within many species (Tabachnick 2002) is not well represented in previous studies. As a consequence, most difficulties in identifying Antarctic rossellid sponges in situ are caused by (a) the lack of diagnostic characteristics distinguishing morphologically similar species and genera, e.g., A. joubini, $R$. nuda and $R$. vanhoeffeni, and (b) large intraspecific variability in some species, e.g., $R$. racovitzae. The superficial similarity of $R$. nuda and A. joubini impedes their differentiation in underwater image material and prompted Teixidó et al. (2006) to lump them together as " $R$. nuda type". Also $R$. vanhoeffeni has been described in many regards similar to R. nuda (Barthel and Tendal 1994). By contrast, $R$. racovitzae is considered highly variable regarding its external morphology and spicules and was suggested to include several cryptic species (Barthel and Tendal 1994; Göcke and Janussen 2013). Indeed, the species $R$. podagrosa, which has long been synonymized with $R$. racovitzae and considered a strongly budding morphotype of the latter, has recently been re-described and re-established as a valid species based on material from the Ross Sea (Göcke et al. 2015). Although this has reduced the morphological variability of $R$. racovit$z a e$, the species is still poorly defined and shows similarities to R. villosa and R. levis (Barthel and Tendal 1994; Göcke and Janussen 2013).

Although the synonymy of most Rossella species is not yet fully resolved and all species of this genus are in dire need of revision (Tabachnick 2002), ecological and biogeographical studies promptly require a practical approach to in-situ species identification without expert taxonomic knowledge. In this paper, we provide a straight-forward guideline to in-situ identification of the most common rossellid sponges of the Antarctic shelf. Based on the current understanding of rossellid taxonomy and combining wellpreserved trawl-collected material with a large number of in-situ images, we describe diagnostic macroscopic characteristics to reliably distinguish the well-established species from each other. Besides confirming previously described morphological features that partly have been neglected, we highlight characteristics which have previously not been recognized as diagnostic. In particular, we focus on resolving the confusion around two problematic cases of abundant species that have been mixed up in the past: (a) A. joubini, $R$. nuda and $R$. vanhoeffeni, and (b) R. racovitzae and $R$. podagrosa.

\section{Materials and methods}

\section{Determination of relevant macroscopic characteristics}

Macroscopic characteristics of Anoxycalyx (Scolymastra) joubini, Rossella nuda and Rossella vanhoeffeni were assessed and validated on the basis of collected specimens identified by spicule analysis (see sections "Sponge collection and examination" and "Spicule analysis"). The observed characteristics were compared with previous reports (Table 1) and their applicability to species identification in in-situ photographs and videos was verified (see section "ROV surveys and image analysis"). Macroscopic characteristics of Rossella racovitzae, Rossella podagrosa and other Rossella species were collated from literature (Table 1) and supplemented by our own observations based on in-situ photographs and videos (see section "ROV surveys and image analysis"). 
Table 1 Most relevant species descriptions consulted and material analyzed for this study (numbers refer to references)

\begin{tabular}{|c|c|c|c|}
\hline Species & Original description & Recent descriptions & Material in this study \\
\hline A. joubini & Short, only main features: 5 & $7,(8), 11$ & Collection; in-situ images \\
\hline R. nuda & One small specimen: 2 & $7,(8), 9,11$ & Collection; in-situ images \\
\hline R. vanhoeffeni & One specimen, very detailed: 4 & 7,8 & Collection; in-situ images \\
\hline R. racovitzae & Very small specimens/fragments: 2 & $7,9,11$ & In-situ images \\
\hline R. podagrosa & Ten specimens, detailed: 3 & 10,11 & In-situ images \\
\hline R. villosa & Twenty specimens, detailed, but habitus only: 6 & 7 & In-situ images \\
\hline R. levis & Four specimens, detailed: 3 & $7,9,11$ & In-situ images \\
\hline R. fibulata & Three small fragments only: 4 & $7,(9), 11$ & In-situ images \\
\hline R. antarctica & Spicules only: 1 ; detailed habitus descriptions: 3,4 & $7,9,11$ & In-situ images \\
\hline
\end{tabular}

1: Carter (1872), 2: Topsent (1901), 3: Kirkpatrick (1907), 4: Schulze and Kirkpatrick (1910), 5: Topsent (1916), 6: Burton (1929), 7: Barthel and Tendal (1994), 8: Teixidó et al. (2006), 9: Göcke and Janussen (2013), 10: Göcke et al. (2015), 11: Dayton et al. (2016)

\section{Sponge collection and examination}

We examined a total of 40 smooth-walled rossellid sponges from the Weddell Sea continental shelf for microand macroscopic differences between A. joubini, R. nuda and $R$. vanhoeffeni (see Online Resource 1 for details and map of trawling locations).

Nineteen undamaged specimens were collected by trawls at ten stations in the eastern Weddell Sea during RV Polarstern expedition PS82 (ANT XXIX/9) in 2013/14 (Knust and Schröder 2014). They were cleaned, photographed, dried on board and stored in sealed plastic bags until further analysis at AWI. To distinguish A. joubini from Rossella, the spicules of all specimens were examined microscopically (see section "Spicule analysis"). Subsequently, we examined the macroscopic characteristics of the specimens and established clear differences between A. joubini and Rossella.

To test the validity of these macroscopic differences, we re-examined 14 dried sponges collected by trawls at two stations in the eastern Weddell Sea during RV Polarstern expedition PS77 (ANT XXVII/3) in 2011 (Knust et al. 2012). Seven of them had been tentatively identified as $A$. joubini (Fillinger et al. 2013: Table S5); the other seven were identified as $R$. vanhoeffeni based on spicule analysis. After sorting the specimens based on macroscopic differences, we examined the spicules of all tentative A. joubini as they appeared to include some $R$. nuda. Photographs of the respective spicule preparations and of all collected sponges are available from the data publisher PANGAEA (Federwisch et al. 2019).

For further validation, we examined the macroscopic characteristics of seven ethanol-preserved Weddell Sea specimens from the collection of Senckenberg Museum, Frankfurt, which had been previously identified by spicule analysis as $R$. nuda $(n=4)$ and A. joubini $(n=3)$.

\section{Spicule analysis}

Spicule preparations were made for A. joubini, R. nuda and $R$. vanhoeffeni. We analyzed duplicate samples of about $1 \mathrm{~cm}^{2}$ from the outer wall of each sponge and, for the alleged A. joubini specimens of PS77 (see "Sponge collection and examination" section), one additional sample from the inner wall to avoid contaminations on the outside (see below). We used 6\% sodium hypochlorite solution to digest the organic material. This approach is much simpler and quicker than the nitric acid-boiling method (BouryEsnault and Rützler 1997) and worked very well for the dried hexactinellid samples. After about $15 \mathrm{~min}$, most of the organic material was dissolved and the spicules were loosely suspended. Each sample was examined with a light microscope (ZEISS Axioskop) at $\times 100$ magnification for the presence of the unique stout spiny dermal hexactins which are diagnostic for A. joubini (Fig. 1; see also Barthel and Tendal 1994: Fig. 52).

It is important to note that spicule preparations of trawlcollected sponges are prone to contamination. If different species are caught in the same trawl, as was the case for the individuals of PS77, tissue erosion on the outer walls may lead to contamination with spicules of other species. This may explain some of the confusion in previous species identifications. A typical dermal spicule preparation of $A$. joubini includes thousands of the diagnostic dermal hexactins. If only small numbers of these hexactins were found scattered throughout a preparation $(<2 \%$ of the numbers found in typical $A$. joubini preparations), they were considered to be contaminations and the sponge specimens were identified as Rossella. Contamination can be reduced or avoided by taking dermal spicule samples from the inner wall of the sponges and where it appears most intact. 


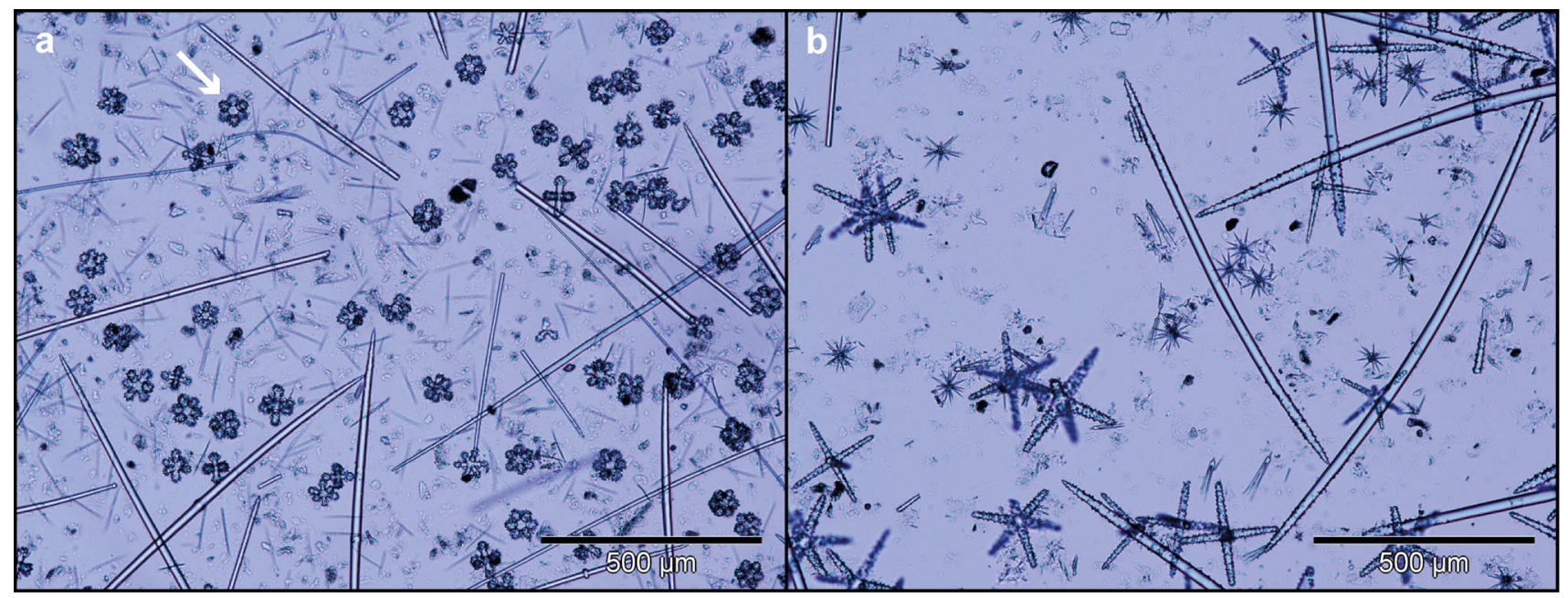

Fig. 1 Typical spicule preparations of a Anoxycalyx (Scolymastra) joubini (specimen Rn11, PS77) showing many of the species' unique dermal hexactins (one marked with an arrow), and b Rossella nuda (specimen Rn16, PS77). Photographs were taken with an Olympus DP70 camera installed on a light microscope (ZEISS Axioskop) and the software Olympus DP-Soft 3.2

\section{ROV surveys and image analysis}

We applied the macroscopic characteristics established on the basis of the trawl-collected specimens in our study and previous reports (Table 1) to in-situ species identification of rossellid sponges in ROV videos and photographs. The image material was collected during several expeditions with RV Polarstern to the Weddell Sea [PS77 in 2011 (Knust et al. 2012), PS82 in 2013/14 (Knust and Schröder 2014), PS96 in 2015/16 (Schröder 2016)]. Figure 2 shows the locations of ROV deployments. Station details and technical details of the respective ROVs can be found in Online Resource 1.

We analyzed a total of 901 high-resolution photographs of rossellid sponges taken selectively during PS77 and selected 146 as reference images representing all species discussed in this study except $R$. fibulata. As photographs were not recorded during PS82 and PS96, we analyzed High-Definition (HD) video material of these expeditions. It included $10 \mathrm{HD}$ video transects of 500-1500 m length conducted during PS82 from which 475 reference images were extracted, displaying all species discussed in this study, and close-up footage of 27 sponges (A. joubini, $R$. nuda, $R$. vanhoeffeni, $R$. racovitzae, $R$. villosa) recorded during PS96 from which 128 reference images were extracted. All reference images are available from the data publisher PANGAEA (Federwisch et al.; see Online Resource 1 for an overview).

\section{Results}

\section{Macroscopic characteristics of collected Anoxycalyx (Scolymastra) joubini, Rossella nuda and Rossella vanhoeffeni}

Based on the spicule preparations of the sponges collected during PS82, three specimens were identified as A. joubini, nine as $R$. nuda, two as $R$. vanhoeffeni and five as Rossella (either $R$. nuda or $R$. racovitzae). The A. joubini and Rossella spp. individuals differed markedly in their basal spicule tuft and in the structure of their outer surface (Fig. 3). In A. joubini, the basal spicule tuft consists of short $(1-5 \mathrm{~cm})$, thin, straight inflexible spicules that may form a compact or loose mass, but no separate strands (Fig. 3a). The structure of the outer surface is regular, dense and coalesced with conspicuously round pores (Fig. 3b). In R. nuda, the basal spicule tuft is considerably longer $(8-30 \mathrm{~cm}$ in the examined individuals) and often soft and flexible. In many individuals it grows, at least partly, in separate strands (Fig. 3c). The outer surface consists of a fine network of irregular angular meshes underlain by a network of larger meshes (Fig. 3d).

These macroscopic characteristics allowed us to separate the seven individuals tentatively identified as $A$. joubini by Fillinger et al. (2013) into two A. joubini and five R. nuda. The macroscopic identification was corroborated by the 
Fig. 2 Station map of remotely operated vehicle (ROV) deployments in the eastern Weddell Sea. The inset shows the location of the study area in the Antarctic. Background: The International Bathymetric Chart of the Southern Ocean (IBCSO) Version 1.0 (Arndt et al. 2013) with $500 \mathrm{~m}$ contour lines

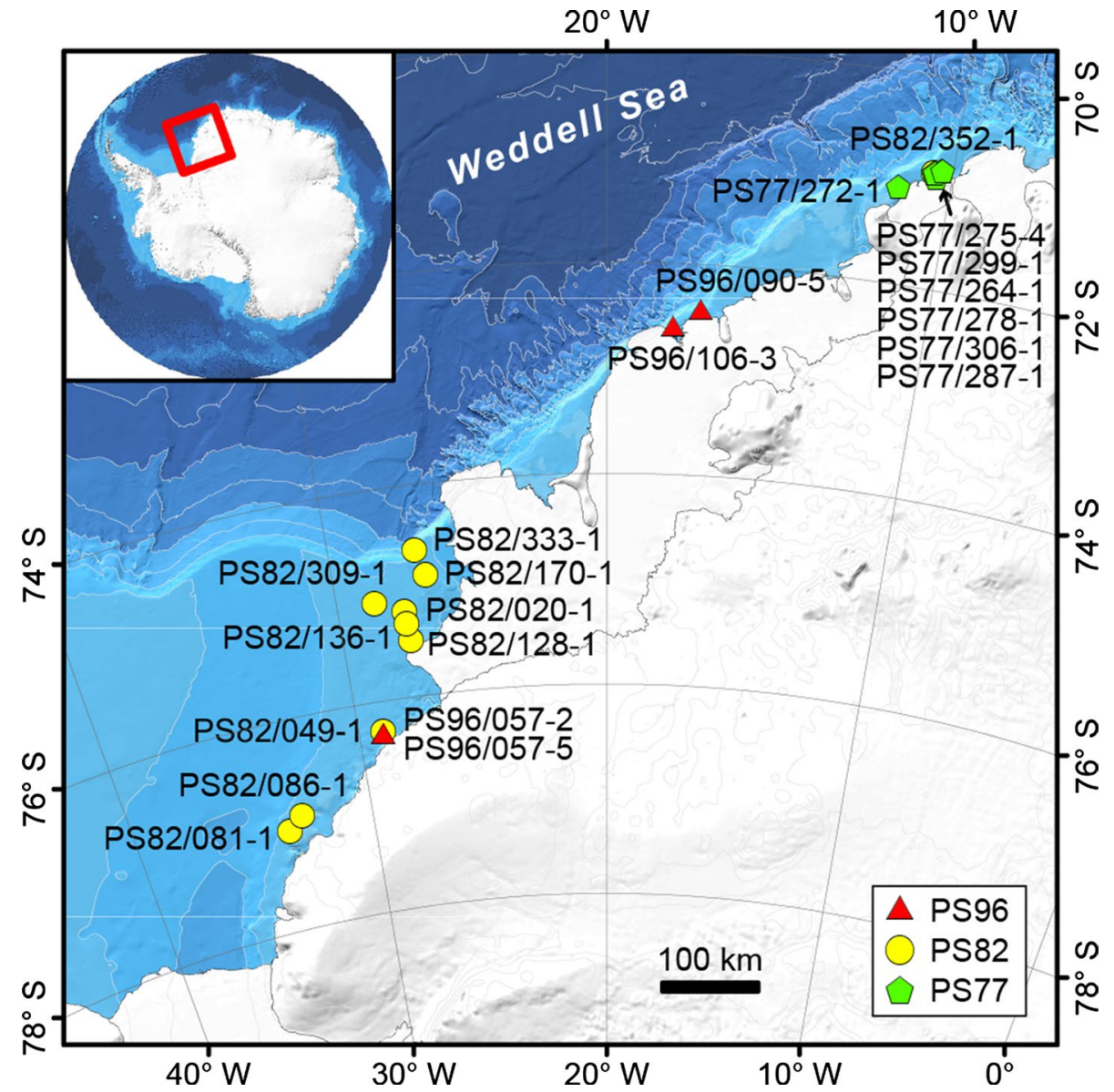

spicule preparations which clearly separated $A$. joubini from R. nuda (Fig. 1). The A. joubini and R. nuda specimens from the collection of Senckenberg Museum showed the same macroscopic characteristics of the outer surface as the conspecifics collected in our trawls, confirming our observations. The basal spicule tuft could not be examined in these specimens, as the basal parts have not been conserved.

Rossella vanhoeffeni has a long and flexible basal spicule tuft similar to $R$. nuda. However, in none of the nine specimens examined it formed distinct separate strands as in $R$. nuda, but it appeared denser and more entwined. The outer surface consists of a network of irregular angular meshes similar to $R$. nuda, but much denser. Furthermore, $R$. vanhoeffeni tends to have a markedly thin and sharp osculum edge, whereas in $R$. nuda it is rather blunt.

The basal spicule tuft and outer surface structure were characteristic in all examined sponges. The structure of the inner surface, however, seems to be more variable. While in all examined $R$. vanhoeffeni the inner surface was covered by a fine network of meshes, only some $R$. nuda specimens showed a mesh structure on the inside, whereas others had a compact inner surface without macroscopically visible meshes. In contrast to this, two of the dried A. joubini individuals of PS82 showed large canal openings on the inside.
Such large canal openings were not observed in any $R$. nuda or $R$. vanhoeffeni specimens (see Federwisch et al. 2019 for photographs of all collected sponges).

The color of all our examined $R$. nuda specimens was gray-white or beige-white (fresh and dried), the A. joubini specimens were beige when fresh and orange or light brown when dried, and the $R$. vanhoeffeni specimens were different shades of brown when fresh and dried. Furthermore, in contrast to A. joubini and $R$. nuda, the freshly collected $R$. vanhoeffeni had a particularly soft and squishy texture and were easily torn or deformed. In A. joubini, the body wall was thicker and more robust with a leathery, incompressible texture, while the body wall of $R$. nuda was intermediately thick and soft.

\section{Macroscopic characteristics of Anoxycalyx (Scolymastra) joubini, Rossella nuda and Rossella vanhoeffeni in situ}

Our investigation of high-resolution photo and video material showed that the macroscopic characteristics observed in trawl-collected specimens can also be observed in situ (Fig. 4). The most conspicuous characteristic for differentiating A. joubini from $R$. nuda and $R$. vanhoeffeni is the 


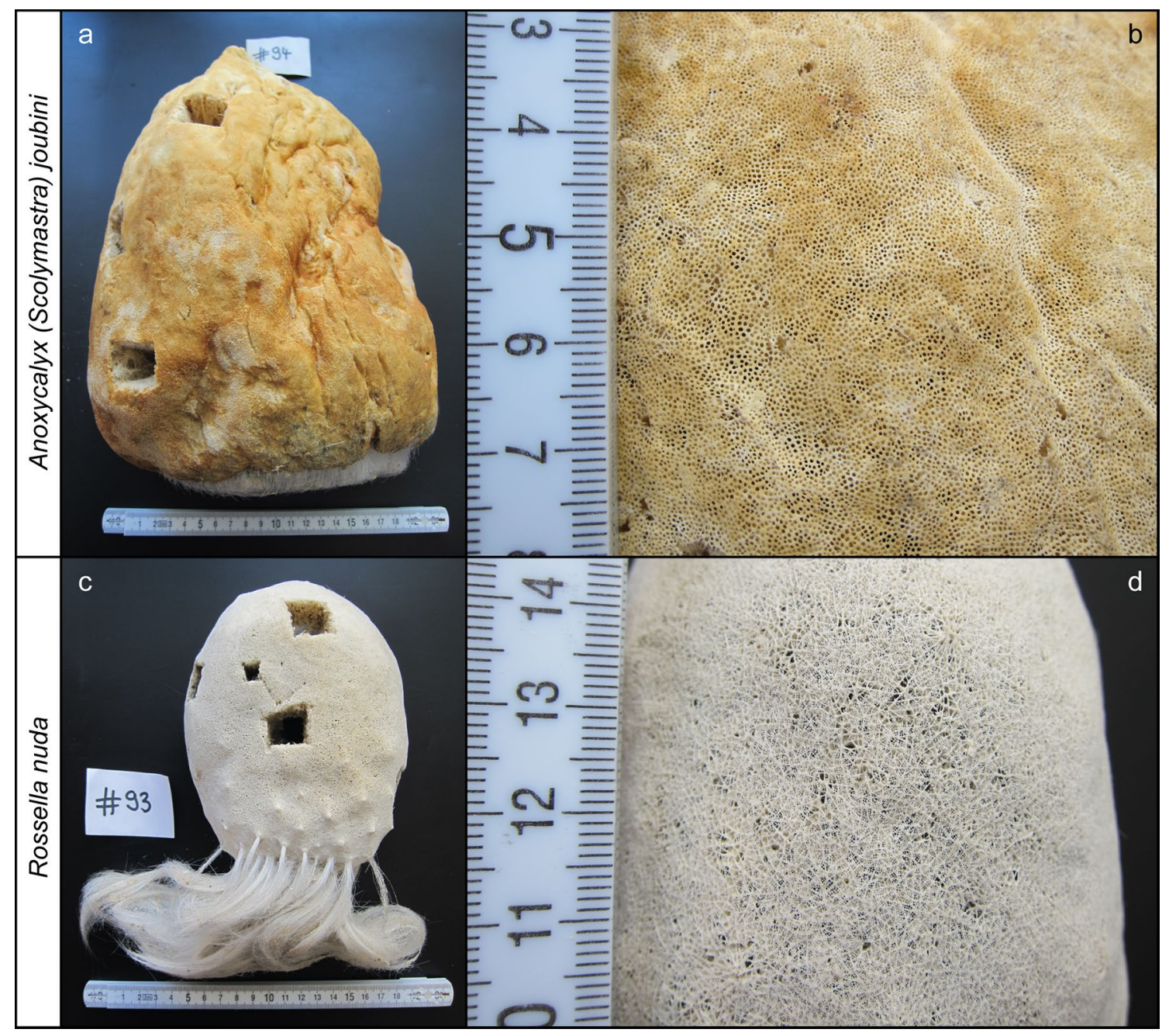

Fig. 3 Macroscopic differences between Anoxycalyx (Scolymastra) joubini $(\mathbf{a}, \mathbf{b})$ and Rossella nuda $(\mathbf{c}, \mathbf{d})$ in dried specimens: a Habitus with short basal spicule tuft. b Close-up of outside wall with typical coalesced structure and round pores. c Habitus with long basal spic-

basal spicule tuft. As this is very short in A. joubini, it is only visible on barren ground and when the sponge is seen from the side (Fig. 4a). Rossella nuda and $R$. vanhoeffeni, in contrast, usually have long basal spicule tufts which are intertwined with the underground (Fig. 4e, i). While in $R$. nuda often, but not always, separate strands of long spicules can be seen (Fig. 4f), it is usually one dense mass of spicules in R. vanhoeffeni (Fig. 4i).

If no basal spicule tuft is visible, A. joubini can be identified by large openings of the excurrent canals on the inside (Fig. 4b), especially in large individuals. Another peculiarity is the distinct fringe of short spicules along the osculum rim of most A. joubini (Fig. 4a, b, c), a feature absent in the other smooth-walled species. We observed both of these characteristics regularly in our in-situ image material. Differences in the osculum edge of $R$. nuda and $R$. vanhoeffeni, ule tuft partly growing in separate strands. d Close-up of outside wall with loose, irregular mesh structure. Numbers on the folding ruler denote centimeters

as described for the dried specimens, are also visible in situ. In $R$. nuda, the osculum edge is often rounded (Fig. 4f, g), while in $R$. vanhoeffeni it tapers out to a thin sharp edge which is of lighter color than the rest of the body (Fig. $4 \mathrm{j}, \mathrm{k}$ ).

The differences in surface structure we described for the collected specimens are also visible in situ, but only on very close inspection (Fig. 4d, h, 1). The outer surface of $A$. joubini looks dense and coalesced, has a regular structure and round pores (Fig. 4d), whereas in $R$. nuda it appears like a loose network of irregular, more angular meshes (Fig. 4h). In $R$. vanhoeffeni, the outer wall appears denser than in $R$. $n u d a$ and the network of meshes may be hardly visible. If the meshes are visible, they are similarly irregular as in $R$. nuda (Fig. 41).

According to our observations, the typical body shape of A. joubini is pear- or barrel-shaped (Fig. 4a, c) and the 


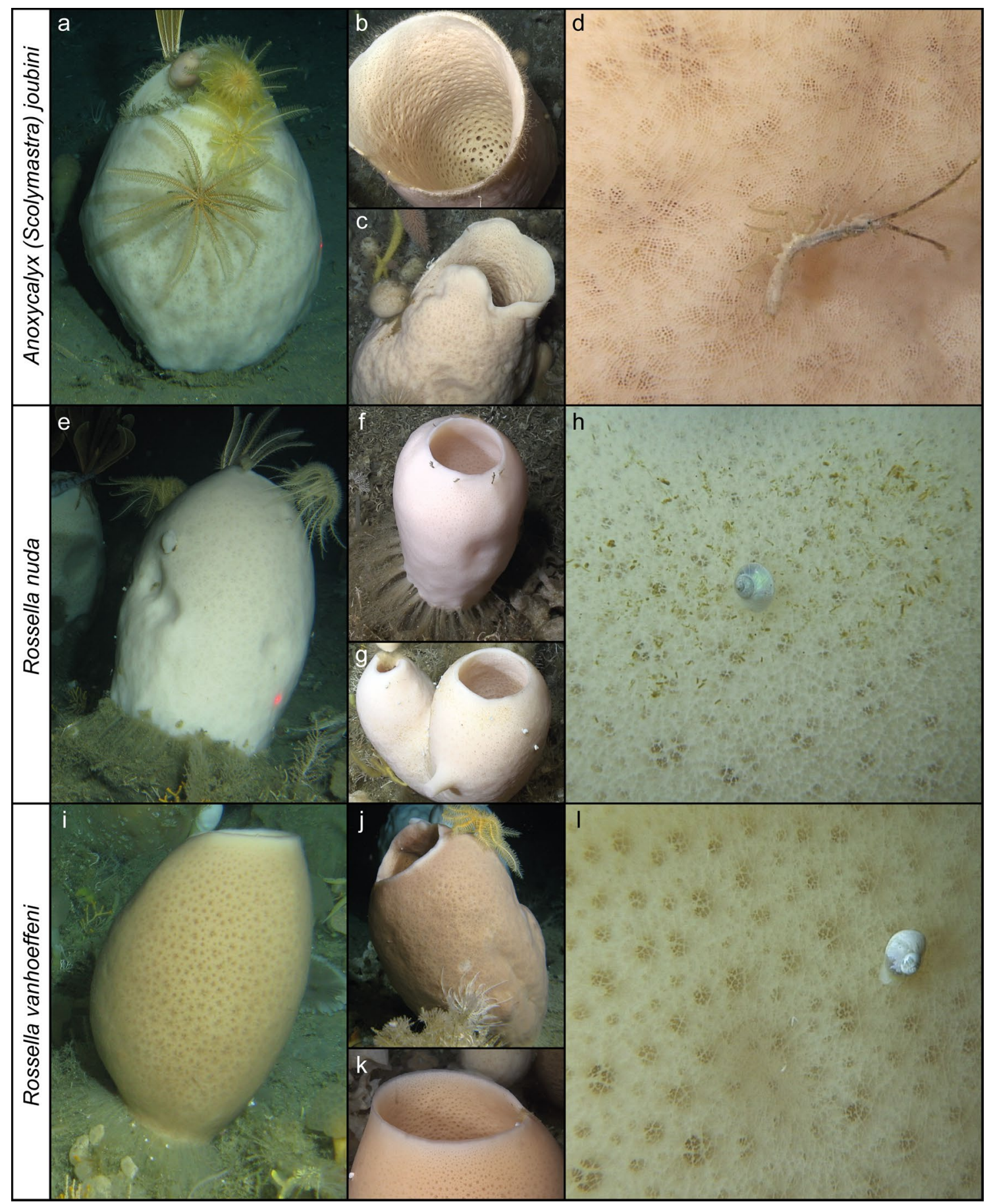

Fig. 4 Macroscopic differences between Anoxycalyx (Scolymastra) joubini (a-d), Rossella nuda (e-h) and Rossella vanhoeffeni (i-l) in situ. d, $\mathbf{h}, \mathbf{l}$ are close-up images of the specimens shown in $\mathbf{c}, \mathbf{g}, \mathbf{k}$, respectively. See text for detailed description

color mostly white or beige, but sometimes also yellowish to light orange. Rossella vanhoeffeni is typically slender and amphora-shaped (Fig. 4i, j) and occurs in different shades of brown. Rossella nuda seems to vary between roundish and elongate, but is generally stouter than $R$. vanhoeffeni (Fig. 4e, f). Some R. nuda specimens have a trumpet-shaped osculum. The color is mostly white or beige, but may also be pinkish or light brown.

All three species have generally smooth walls, but of different thicknesses. In $R$. nuda, the wall usually looks thicker and the transverse canals towards the outside are not shining through as much as in R. vanhoeffeni (Fig. 4). 
When individuals of both species were growing next to each other, the canals looked larger in $R$. vanhoeffeni than in $R$. nuda (compare also Fig. $4 \mathrm{~h}, 1$ ). The very soft texture of $R$. vanhoeffeni may be visible in ROV-recorded videos, as the sponge body tends to wobble due to currents induced by a close-by ROV. Anoxycalyx (Scolymastra) joubini typically has a very thick wall which, especially in large specimens, looks robust and somewhat leathery or fleshy and may show bumps and wrinkles. A tabulated summary comparing the diagnostic features of A. joubini, $R$. nuda and $R$. vanhoeffeni is provided in Table 2.

Based on these macroscopic characteristics, we could clearly distinguish all A. joubini from $R$. nuda in the studied ROV photographs and videos. Rossella nuda and $R$. vanhoeffeni could generally be well distinguished, except for a few small specimens lacking typical characteristics (see "Discussion" section). All smooth-walled budding sponges we observed were clearly Rossella (most likely $R$. nuda). They could usually be identified by their long basal spicule tuft or a combination of other Rossella characteristics. Many of them had a remarkable pinkish color. None of the budding sponges showed any of the typical characteristics of A. joubini.

\section{Macroscopic characteristics of Rossella racovitzae, Rossella podagrosa and similar species in situ}

Rossella racovitzae and $R$. podagrosa can easily be distinguished in in-situ image material based on their external morphology (Fig. 5). Rossella racovitzae is typically barrel-shaped and characterized by more or less pronounced conules and more or less protruding spicule bundles. The overall morphology is highly variable. We documented several morphotypes: small to intermediate-sized regular conules with some protruding spicules (Fig. 5a), low density of very flat conules with protruding spicules (Fig. 5b), low density of thin, strongly pointed conules with some protruding spicules (Fig. 5c), long finger-like conules with protruding spicules (Fig. 5d), long thick, partly dividing conules, (mostly) without protruding spicules (Fig. 5e), and very large (sometimes broad and flat) regular conules without protruding spicules (Fig. 5f). The form and distribution of conules over the body surface may be regular or irregular; long conules are sometimes bent (e.g., Fig. 5d). There may be gradual transitions between these morphotypes and to the typical morphologies of $R$. villosa and $R$. levis, both characterized by conules with protruding spicule bundles. We regularly observed the different morphotypes of $R$. racovitzae at the same location or even in close vicinity to each other. There was no obvious pattern in the local and regional distribution of the different morphotypes.

Table 2 Macroscopic characteristics of species with smooth outside walls without conules: Anoxycalyx (Scolymastra) joubini, Rossella nuda, Rossella vanhoeffeni

\begin{tabular}{|c|c|c|c|}
\hline & A. joubini & R. nuda & R. vanhoeffeni \\
\hline Basal spicule tuft & $\begin{array}{l}\text { Short, thin, straight inflexible spic- } \\
\text { ules forming a compact or loose } \\
\text { mass }\end{array}$ & $\begin{array}{l}\text { Long, flexible, intertwined with } \\
\text { underground; often in separate } \\
\text { strands }\end{array}$ & $\begin{array}{l}\text { Long, flexible, intertwined with under- } \\
\text { ground; usually one dense mass }\end{array}$ \\
\hline Outer surface & $\begin{array}{l}\text { Dense and coalesced, with regular } \\
\text { structure and round pores }\end{array}$ & $\begin{array}{l}\text { Loose network of irregular, angular } \\
\text { meshes }\end{array}$ & $\begin{array}{l}\text { Network of irregular meshes, appears } \\
\text { relatively dense; meshes may be } \\
\text { hardly visible }\end{array}$ \\
\hline Osculum edge & Often with fringe of short spicules & $\begin{array}{l}\text { Without spicule fringe; blunt/ } \\
\text { rounded edge }\end{array}$ & $\begin{array}{l}\text { Without spicule fringe; thin sharp } \\
\text { edge with lighter color }\end{array}$ \\
\hline Inner surface & $\begin{array}{l}\text { Often with large openings of excur- } \\
\text { rent canals }\end{array}$ & $\begin{array}{l}\text { Covered by a fine network of } \\
\text { meshes, or compact without visible } \\
\text { meshes }\end{array}$ & Covered by a fine network of meshes \\
\hline Wall thickness and texture & $\begin{array}{l}\text { Thick, robust; with leathery/fleshy, } \\
\text { incompressible texture; may have } \\
\text { bumps and wrinkles }\end{array}$ & Intermediately thick and soft & $\begin{array}{l}\text { Rather thin; with soft, squishy texture; } \\
\text { easily torn or deformed }\end{array}$ \\
\hline Body form & Pear-shaped/barrel-shaped & $\begin{array}{l}\text { Roundish or elongate, rather stout; } \\
\text { sometimes with trumpet-shaped } \\
\text { osculum }\end{array}$ & Slender, amphora-shaped \\
\hline Color (in situ) & $\begin{array}{l}\text { Mostly white/beige, sometimes yel- } \\
\text { lowish/light orange }\end{array}$ & $\begin{array}{l}\text { Mostly white/beige, sometimes pink- } \\
\text { ish/light brown }\end{array}$ & Different shades of brown \\
\hline Further remarks & $\begin{array}{l}\text { Juveniles have protruding spicules } \\
\text { over their whole body surface }\end{array}$ & $\begin{array}{l}\text { Regularly observed with several to } \\
\text { numerous buds }\end{array}$ & $\begin{array}{l}\text { Very large specimens may be rather } \\
\text { barrel- or pear-shaped and more } \\
\text { robust }\end{array}$ \\
\hline
\end{tabular}




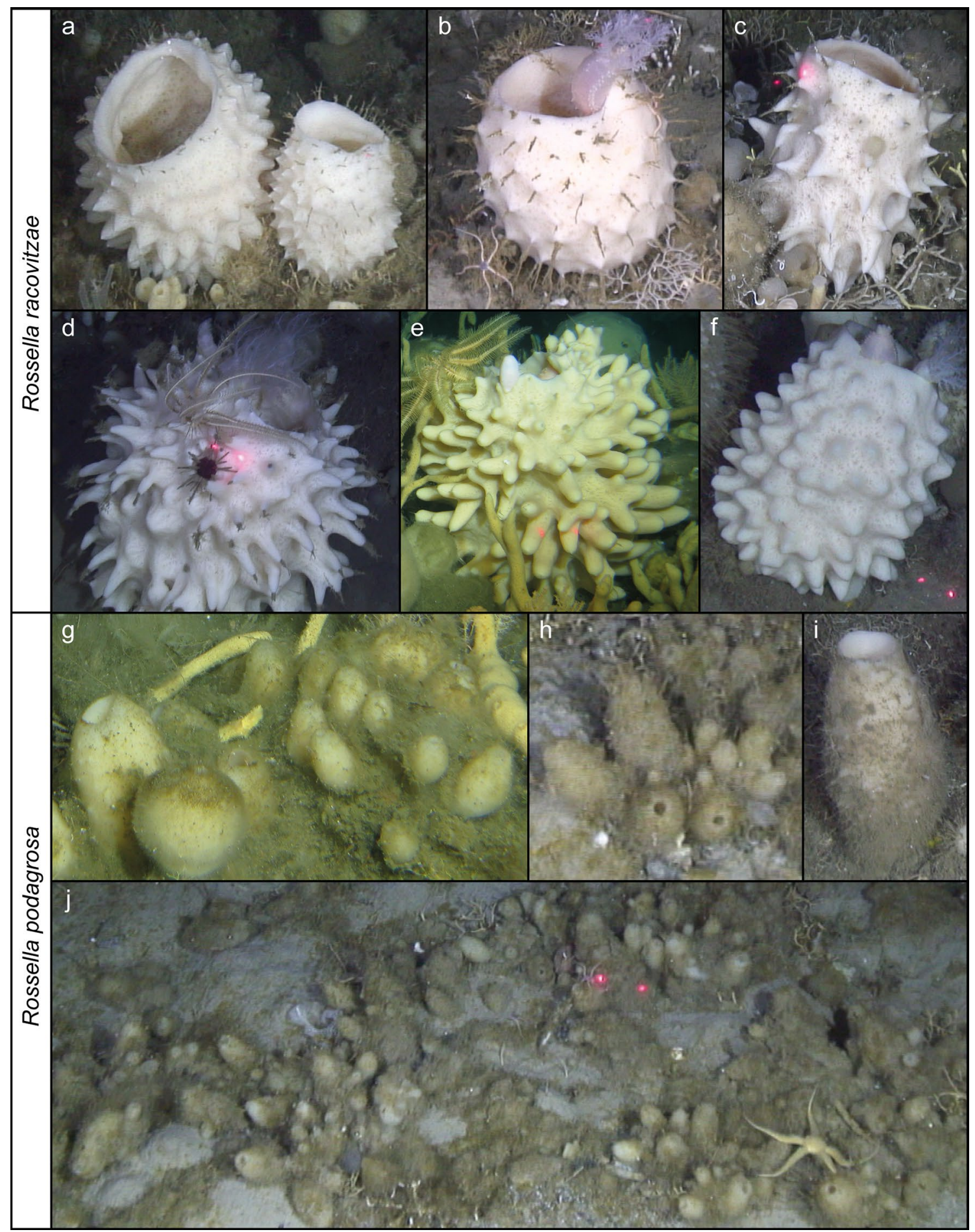

Fig. 5 Macroscopic variability of Rossella racovitzae (a-f) and different growth forms of Rossella podagrosa (g-j) in situ. See text for detailed description

Rossella podagrosa, in contrast, has a distinct habitus which is very different from $R$. racovitzae: the body shape is mostly slender and elongate with a small osculum and without any conules (Göcke et al. 2015). Its surface is rough and covered by a thin spicule veil which collects sediment and organic debris and gives the sponge a dirty appearance (Fig. 5g-j), distinguishing this species from all others presented so far. At locations with thick spicule mats, small specimens of $R$. podagrosa were difficult to detect. The most striking characteristic of this species is its budding: it usually 
occurs in groups of several individuals of different size (Fig. 5g) which sometimes are attached to each other at the base (Fig. $5 \mathrm{~h}$ ). However, we also observed single individuals which were markedly larger than the specimens in budding groups, but otherwise resembled them closely (Fig. 5i). Rossella podagrosa was most abundant at stations with particularly soft sediment, where it formed extensive aggregations (Fig. 5j). It was considerably rarer at stations with hard substrate (gravel, stones, bryozoan cover), where we observed only a few of the single specimens, but no budding groups. Although the abundance varied between very low and very high, it was present in nine of the ten video transects of PS82 and thus widely distributed. Detailed descriptions of the ROV video transects, including the observed growth forms of $R$. podagrosa, can be found in Online Resource 1. Rossella racovitzae occurred at the same stations, but it was less variable in its abundance and the single specimens typically grew some distance apart from each other. We did not observe any form of budding in $R$. racovitzae.

While the macroscopic differences between $R$. racovit$z a e$ and $R$. podagrosa are obvious, $R$. racovitzae may be confused with $R$. villosa or $R$. levis. However, in contrast to the high morphological variability of $R$. racovitzae, the morphology of $R$. villosa seems homogenous: the whole body surface is densely covered with straight spicule bundles protruding from tiny conules which may be hardly visible in small specimens (Fig. 6a-c). The spicule bundles may be short or long (Fig. 6b), but the length does not vary much within an individual. The sponge body is rounded or barrel-shaped with a blunt or rounded osculum rim. Rossella levis, in contrast, has an elongate or conical body shape which usually gets narrower towards the osculum and ends in a thin osculum rim. The conules with protruding spicule bundles are small, but more pronounced than in $R$. villosa, and markedly pointed (Fig. 6d-f). They are regularly distributed over its surface, but less dense than in $R$. villosa. Moreover, the length of the protruding spicules varies notably: in the upper part of the body they are short or absent, getting longer towards the lower half, and at the base distinct bundles of very long, flexible spicules originate from the conules. These anchoring spicule bundles are sometimes visible in situ (Fig. 6d-f). Rossella villosa, in contrast, tends to have a fuller basal spicule tuft, which, however, is less well visible in situ. Regarding color, $R$. racovitzae appears most variable with shades of white, yellowish, beige and light brown, while we observed only white $R$. villosa and white to yellowish $R$. levis. In difficult cases of differentiating these three species, density and length of the protruding spicule bundles seem to be the most helpful characteristics.

Another species with pronounced conules, but the only one with an unmistakable appearance is R. fibulata (Fig. $6 \mathrm{~g}-\mathrm{i}$ ). It is characterized by a dark brown color and big ridge-like, laterally flattened (not conical) conules without protruding spicules. The conules are most pronounced in the lower part of the body where the sponge is usually widest. Towards the osculum it gets narrower and the wall gets thinner. The excurrent canal openings are visible on the inside of large specimens, similar to large A. joubini.

The only currently established Rossella species that $R$. podagrosa may be confused with when specimens are small is $R$. antarctica. This species also bears a veil of protruding spicules and may look dirty (Fig. 6j-1). However, $R$. antarctica typically has a rounded shape and the spicule veil is more pronounced than in $R$. podagrosa. While large specimens look clearly different from each other, the macroscopic differences are less obvious in small individuals (compare small $R$. antarctica on the left in Fig. 6j and $R$. podagrosa in Fig. 5h). According to our observations, $R$. antarctica usually occurs as single individuals standing by themselves and there is no budding in this species. A tabulated summary comparing the diagnostic features of the described species is provided in Tables 3 and 4 .

\section{Discussion}

Our investigation of macroscopic differences between similar rossellid sponge species shows that each species has unique characteristics by which it can be identified in situ and without expert taxonomic knowledge. In contrast to previous studies which just mention some characteristics of selected species (e.g., Göcke and Janussen 2013; Dayton et al. 2016), we provide the first comprehensive overview of macroscopic characteristics of all rossellid species common to the Antarctic shelf based on a large number of insitu photographs and videos (Federwisch et al. 2019). The described characteristics are conspicuous and occur not just locally, but in various locations studied during three different expeditions from 2011 to 2016.

Sponges exhibiting different macroscopic characteristics were often growing in close vicinity or even right next to each other (Fig. 7). In these cases, the differences between similar species, e.g., R. nuda and $R$. vanhoeffeni (Fig. 7a, b) or $R$. villosa and R. levis (Fig. 7c), were especially apparent. Even larger mixed groups of several species, each showing their specific macroscopic characteristics, occurred regularly (Fig. 7d). Therefore, we are confident that these characteristics are species-specific and not just local ecotypes or random variations, supporting the view of Göcke and Janussen (2013) on this subject.

\section{Macroscopic characteristics and variability of Anoxycalyx (Scolymastra) joubini, Rossella nuda and Rossella vanhoeffeni}

The macroscopic differences we describe between $A$. joubini, $R$. nuda and $R$. vanhoeffeni were first discovered in 


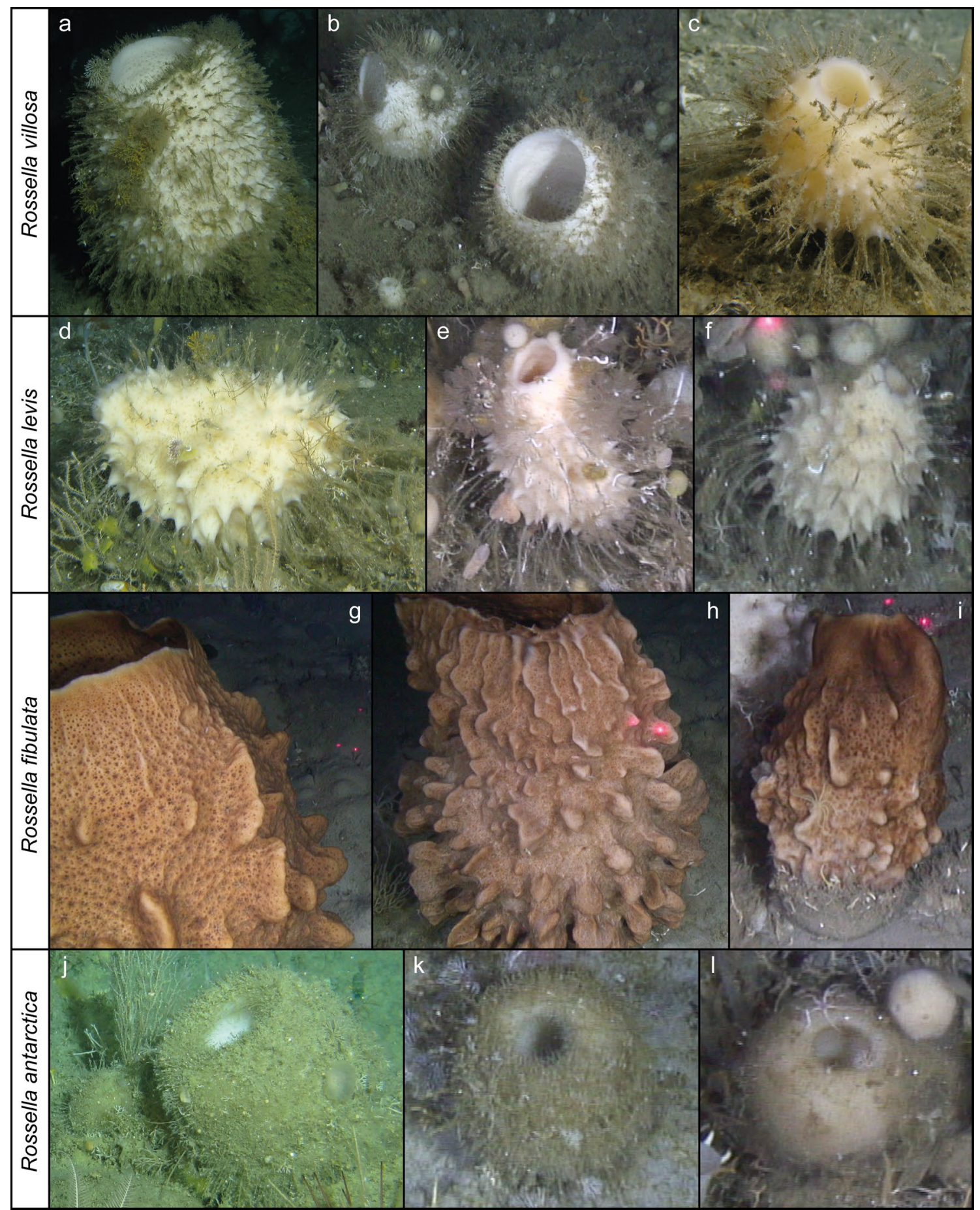

Fig. 6 Macroscopic characteristics of Rossella villosa $(\mathbf{a}-\mathbf{c})$, Rossella levis $(\mathbf{d}-\mathbf{f})$, Rossella fibulata $(\mathbf{g}-\mathbf{i})$ and Rossella antarctica (j-l) in situ. See text for detailed description

dried specimens identified by spicule analysis. Thus, we are sure that they are species-specific and a clear means to distinguish these species. Surprisingly, some of these conspicuous differences either seem to have evaded sponge researchers until now or their value for species identification was not recognized (e.g., Teixidó et al. 2006), as they were not consistently reported nor discussed in taxonomic literature so far. Once noticed, the differences are obvious and especially the basal spicule tuft is helpful for distinguishing $A$. joubini from Rossella in image material.

Corresponding to our observations, both Barthel and Tendal (1994) and Teixidó et al. (2006) report a "short, but 
massive" or "broad" basal spicule tuft for A. joubini. Previous descriptions of the basal spicule tuft of $R$. nuda are less informative, saying either that it is "weakly developed" (Teixidó et al. 2006) or "varies in size" (Barthel and Tendal 1994). The original description by Topsent (1901) is based on one individual with slender, root-like prolongations of the body instead of a spicule tuft. For $R$. vanhoeffeni, Teixidó et al. (2006) do not mention the spicule tuft at all, but Barthel and Tendal (1994) show two specimens with "entwined, very massive spicule tufts" matching the species description by Schulze and Kirkpatrick (1910) and our observations.

It is important to note that while A. joubini is a lophophytose species, i.e., it always has a basal spicule tuft, Rossella species can be lophophytose or basiphytose, i.e., directly attached to hard substrate without a spicule tuft (Tabachnick 2002). We have observed a few $R$. nuda with the body directly attached to stones and partly overgrowing them, thus lacking a basal spicule tuft, but according to our image material this seems to be a rare phenomenon. Therefore, if no spicule tuft is visible, one has to refer to other typical characteristics that differentiate A. joubini from Rossella, e.g., the fringe of spicules along the osculum rim, which is also reported in the original description by Topsent (1916) and confirmed by Barthel and Tendal (1994), or the large canal openings on the excurrent side. The latter are not specifically mentioned in previous publications, but they have been documented in photographs of A. joubini in the Ross Sea (Brueggeman 2019) corroborating our observations. However, while both characteristics can be observed regularly, they are not present in all individuals.

If none of the above-mentioned prominent characteristics are visible, distinguishing A. joubini from $R$. nuda is more difficult, but still possible on the basis of body form, surface and size. Anoxycalyx (Scolymastra) joubini is the largest sponge species in the Antarctic (Dayton et al. 2016) growing up to $2 \mathrm{~m}$ in height. Rossella nuda and $R$. vanhoeffeni are considerably smaller with up to $75 \mathrm{~cm}$ and $30 \mathrm{~cm}$, respectively (Barthel and Tendal 1994). The relative sizes we observed for these species match previous reports. In the eastern Weddell Sea, A. joubini seems to be less common than $R$. nuda (A. joubini was present in five and $R$. nuda in eight of the ten ROV video transects of PS82).

Rossella vanhoeffeni was considered a valid species by Barthel and Tendal (1994) and was identified by Teixidó et al. (2006) in their image material. However, Göcke and Janussen (2013) suggested that it might be a variety of $R$. racovitzae based on spicule morphology and size. The sponges we describe as $R$. vanhoeffeni have a distinct outer morphology and are common in the eastern Weddell Sea. Our characterization corresponds with the original species description and illustration by Schulze and Kirkpatrick (1910). Besides a "well-developed root-tuft" of $10 \mathrm{~cm}$ length enclosing bryozoan debris and worm tubes, 
Table 4 Macroscopic characteristics of species with a veil of protruding spicules, often dirty-looking, without conules: Rossella podagrosa, Rossella antarctica

\begin{tabular}{lll}
\hline & R. podagrosa & $R$. antarctica \\
\hline Growth form & $\begin{array}{c}\text { Typically in budding groups or large aggregations of individuals of dif- } \\
\text { ferent sizes; sometimes partly hidden in spicule mat } \\
\text { Body form } \\
\begin{array}{c}\text { Mostly slender and elongate, slightly narrower towards the small oscu- } \\
\text { lum }\end{array}\end{array}$ & $\begin{array}{c}\text { Typically rounded } \\
\text { Outer surface }\end{array}$ \\
$\begin{array}{l}\text { Rough, covered by a thin spicule veil, collecting sediment and organic } \\
\text { debris }\end{array}$ & $\begin{array}{c}\text { With pronounced spicule veil, collecting sediment and } \\
\text { organic debris }\end{array}$ \\
\hline
\end{tabular}

similar to our collected specimens, they also describe an amphora-like shape and a sharp osculum edge. The outer surface of their specimen consists of a fine network of irregular, tri- or quadrangular meshes of $1 \mathrm{~mm}$ width with round canal openings of $1-3 \mathrm{~mm}$ width beneath. These larger meshes are covered by a finer network with mesh diameters of $0.15-0.2 \mathrm{~mm}$. This finer network was visible in our dried specimens, but apparently too delicate to be seen in the in-situ image material. Schulze and Kirkpatrick (1910) further report that the canal openings are very small in the upper part of the sponge and not visible near the osculum, where the body wall is opaque and not porous, which matches our observations of $R$. vanhoeffeni specimens examined in situ with close-up video. Overall, we are confident that this species is well justified and the common sponges of usually brown color truly are $R$. vanhoeffeni.

Besides the many typical representatives of $R$. vanhoeffeni, we observed some large smooth-walled brown specimens at several locations which did not show the marked features characterizing this species. They were rather barrel- or pear-shaped and appeared more robust, similar to $A$. joubini, but they lacked any of the typical characteristics of A. joubini. We assume that the atypical appearance is due to the larger size (and possibly higher age) of these specimens and assigned them to $R$. vanhoeffeni as this seemed most fitting. However, we cannot rule out the possibility that they belong to another, potentially undescribed, species.

Corresponding to our observations of $R$. nuda, Topsent (1901) describes the surface of this species as smooth, but slightly uneven and rough, with many "rounded pores" of 0.5-1.5 mm size and 0.5-1 $\mathrm{mm}$ distance to each other, covered by a thin, transparent "ectosome" which is perforated by "microscopic stomions". The "ectosome" is the dermal membrane; the "microscopic stomions" correspond to the meshes in the dermal membrane and the "rounded pores" refer to the canal openings. This supports our assumption derived from in-situ observations that the canal openings are smaller in $R$. nuda $(0.5-1.5 \mathrm{~mm})$ than in $R$. vanhoeffeni (1-3 mm). It further corroborates our macroscopic differentiation between both species and can serve as another valuable characteristic. Unfortunately, the surface and pores of $A$. joubini are not mentioned in the original species description (Topsent 1916).

In a few cases of small and light-brown smooth Rossella, we could not confidently identify them as $R$. vanhoeffeni or $R$. nuda, as small specimens may not show clear characteristics of either species. Many Antarctic hexactinellids change their external morphology during growth from juveniles to adults and distinctive macroscopic features are only developed with increasing size and age (Göcke and Janussen 2013). Usually, however, $R$. vanhoeffeni and $R$. nuda have clearly different and distinct appearances and can reliably be distinguished by a combination of color, body shape, wall thickness and sharpness of the osculum edge. Although these features are variable and none of them alone is a reliable basis for species identification, we are sure that the sponges we describe as $R$. vanhoeffeni and $R$. nuda are clearly different species. This is underpinned by the distinct morphotypes growing next to each other (Fig. 7a, b, d), sometimes with differently developed basal spicule tufts on the same ground and strong budding in $R$. nuda, but not in R. vanhoeffeni.

Changes in macroscopic characteristics during growth may also hamper the identification of young A. joubini. The species is commonly considered to have smooth walls without protruding spicules, except for the short ones along the osculum rim in some individuals. However, young A. joubini do show protruding spicules over the whole body surface which are apparently lost during growth (P. Dayton, pers. comm.). We did not identify any young $A$. joubini in our image material and we cannot say with certainty whether none were present or whether we misidentified them as young $R$. racovitzae or $R$. villosa. According to our observations, $R$. nuda and $R$. vanhoeffeni already seem to be smoothwalled as juveniles.

The smooth-walled species are further characterized by different tissue textures which can be helpful for divers or for macroscopic identification of collected specimens. Our observations of the texture of $A$. joubini (thick, robust, almost incompressible), $R$. nuda (thinner, softer) and $R$. vanhoeffeni (very soft and squishy, wobbly) correspond with the descriptions by Barthel and Tendal (1994) and Teixidó et al. (2006). 


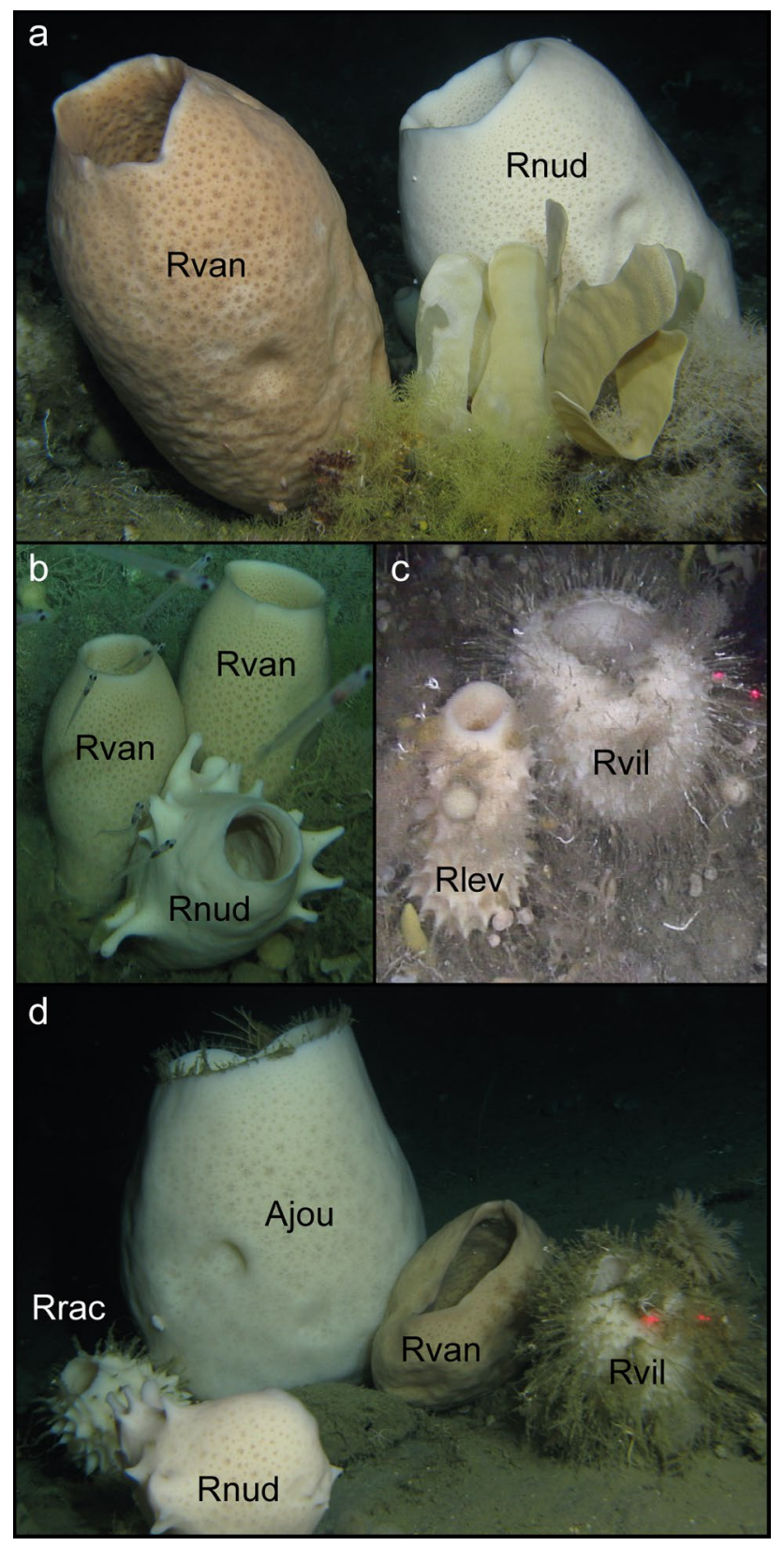

Fig. 7 Different species growing in close vicinity to each other. Note the distinct morphological characteristics: a, b Rossella vanhoeffeni (Rvan) and Rossella nuda (Rnud) c Rossella levis (Rlev) and Rossella villosa (Rvil) d Anoxycalyx (Scolymastra) joubini (Ajou), Rossella racovitzae (Rrac), Rossella nuda (Rnud), Rossella vanhoeffeni (Rvan) and Rossella villosa (Rvil)

\section{Macroscopic characteristics and variability of Rossella racovitzae, Rossella podagrosa and similar species}

To distinguish the species $R$. racovitzae, $R$. podagrosa, $R$. villosa, R. levis, $R$. fibulata and $R$. antarctica on our image material, we used macroscopic features described previously
(Table 1). In contrast to previous descriptions based on limited trawl-collected material, we highlight the macroscopic differences we observed regularly in situ and found useful to identify the species.

Rossella racovitzae has been reported as highly variable regarding its macroscopic characteristics (Barthel and Tendal 1994; Teixidó et al. 2006; Göcke and Janussen 2013). Göcke and Janussen (2013) have even ruled out the possibility to identify the species based on macroscopic features alone. On the other hand, they have characterized it as barrel-shaped and bearing conules, same as Teixidó et al. (2006) and Dayton et al. (2016). The description of the conules, however, differ: they are commonly pointed, but can also be small and indistinct in small specimens or faintly developed in large specimens without protruding spicules apart from the root tuft (Göcke and Janussen 2013), or clearly developed (Göcke et al. 2015), or relatively short (Dayton et al. 2016), or they may bear long protruding spicule bundles (Teixidó et al. 2006). The original species description is based on tiny individuals and fragments with flat conical elevations and protruding spicules (Topsent 1901).

Our current understanding of $R$. racovitzae comprises all of these descriptions and reflects the reported morphological variability (Fig. 5a-f). This variability partly results from many synonymizations, but may also be due to potential cryptic species currently included under this name (Göcke and Janussen 2013) which may represent different morphotypes. This means that with the current state of knowledge, we cannot rule out the possibility that some of the morphotypes denominated as $R$. racovitzae may actually be different species, e.g., the morphotype shown in Fig. $5 \mathrm{f}$ which corresponds to the sponges called "smooth volcano" by Dayton et al. (2016). A recent molecular survey of common Rossella species found $R$. racovitzae to show up in several different clades within the genus, indicating this species to be a polyphyletic species complex (Vargas et al. 2017). Moreover, Barthel and Tendal (1994) based their species descriptions only on material from the Weddell Sea and may have synonymized species which they simply did not find in their collections, but which occur elsewhere, like $R$. podagrosa (Göcke et al. 2015).

The morphological differences between $R$. racovitzae and $R$. podagrosa are so distinct that we could easily distinguish them in our analyzed photographs and videos. The habitus of our described $R$. podagrosa corresponds with the images presented by Kirkpatrick (1907) and Göcke et al. (2015) of specimens from the Ross Sea. We provide the first direct record of $R$. podagrosa in the Weddell Sea, confirming the habitus and growth form observed in the Ross Sea (Göcke et al. 2015). However, it is also possible to identify $R$. podagrosa in older image material with lower quality. The problem in this case is that due to the former synonymization, older records of $R$. racovitzae often include $R$. podagrosa. In the 
Ross Sea, Dayton et al. (1974) and Dayton (1979) reported high abundances and biomass, as well as strong growth and reproduction for small budding specimens of $R$. racovit$z a e$, which were retrospectively identified as $R$. podagrosa (Göcke et al. 2015). Also several studies from the Weddell Sea mention a " $R$. racovitzae budding type" (e.g., Barthel 1992; Barthel and Gutt 1992; Gutt and Koltun 1995; Teixidó et al. 2006). The descriptions and images of these sponges clearly correspond to the re-description of $R$. podagrosa by Göcke et al. (2015) and to our observations of this species. The same budding sponges were falsely referred to as $R$. racovitzae by Maldonado et al. (2016). Therefore, we want to emphasize that older records of $R$. racovitzae should be treated with caution.

Our own observations together with the records of the " $R$. racovitzae budding type" show that $R$. podagrosa is a common species in the eastern Weddell Sea. Contrary to the speculation of Göcke et al. (2015), its main occurrence range is not limited to the Ross Sea. We found it to be most abundant in areas with soft sediment, corresponding to the observations of Barthel (1992), where it formed large aggregations similar to the ones in the Ross Sea (Dayton et al. 1974, 2016; Dayton 1979). In such areas, other hexactinellid species may be disadvantaged due to lacking possibilities of attachment.

Although $R$. podagrosa usually forms buds and grows in groups of individuals attached to each other, as also described by Kirkpatrick (1907) and Göcke et al. (2015), we observed several single specimens without buds at stations with hard substrate. They seem to grow larger than the budding ones, but otherwise look very similar. Such single individuals have not been reported by other studies. We cannot rule out the possibility that these specimens represent another undescribed species of Rossella or possibly Rhabdocalyptus sp. or a related species. However, considering the currently well-established species of Rossella, they show the closest resemblance to $R$. podagrosa.

Distinguishing $R$. racovitzae from $R$. villosa and $R$. levis may be more challenging. We have described the typical characteristics of each species, but transitional forms between them and the lack of defined morphological boundaries of the variable $R$. racovitzae may hamper a clear identification. Nevertheless, the typical habitus of $R$. villosa is unique, as no other species shows such a dense cover of protruding stout spicule bundles. Our macroscopic description of the species is in full accordance with the original description by Burton (1929) and the most recent one by Barthel and Tendal (1994). Interestingly, Burton (1929) described the species based on its "distinctive external appearance", although he did not find notable differences in the spicules between $R$. villosa and $R$. nuda. Koltun (1976) synonymized it with $R$. racovitzae, but Barthel and Tendal (1994) re-established it and added information about the spicules. Despite the uncertain validity of $R$. villosa as a species, sponges of this distinct habitus are common in the eastern and western Weddell Sea (this study and Fillinger et al. 2013, respectively) and occur next to $R$. racovitzae and $R$. levis.

Rossella levis may be the most difficult species to identify in situ, as the characteristic long and separate spicule bundles which anchor the sponge to the substrate may not always be visible. However, our description of this species corresponds to previous descriptions and illustrations (Kirkpatrick 1907; Barthel and Tendal 1994; Göcke and Janussen 2013). The differences in shape and color which we noted between $R$. villosa and R. levis (Fig. 7c) are supported by earlier descriptions, as well: The particularly round shape of R. villosa is mentioned by Burton (1929) and Barthel and Tendal (1994), while Dayton et al. (2016) describe R. levis as tapering in at the top. Furthermore, the pale yellow color of $R$. levis which is most obvious when seen next to other sponges has been reported before (Kirkpatrick 1907; Barthel and Tendal 1994).

Interestingly, one large specimen of $R$. levis is described by Kirkpatrick (1907) with conules forming "large, thick, thumb-like projections" and Dayton et al. (2016) report conules of $10-15 \mathrm{~cm}$ on larger individuals. We have not observed such large conules in R. levis, but we also did not observe particularly large individuals of this species. However, several large specimens which we identified as $R$. racovitzae showed markedly long, finger-like conules and were of pale yellow color (Fig. 5e). As they did not show any other characteristics of $R$. levis (no protruding spicules, no anchoring spicule tufts), we considered them as one of the many morphotypes of $R$. racovitzae. This illustrates the necessity of a thorough taxonomic re-evaluation and better delimitation of $R$. racovitzae, $R$. levis and $R$. villosa.

One example of a good and useful species re-evaluation is $R$. fibulata. The original description by Schulze and Kirkpatrick (1910) was based only on tiny fragments and did not include any information about the species' habitus. Barthel and Tendal (1994) included macroscopic characteristics in their description which we observed as well. The species does not seem to vary much; it looks the same in the Ross Sea (Dayton et al. 2016; Brueggeman 2019) and is always easy to identify.

Another easily identifiable species without much macroscopic variation is $R$. antarctica. The characteristics we describe match the early descriptions and illustrations (Carter 1872; Kirkpatrick 1907; Schulze and Kirkpatrick 1910) as well as recent ones (Göcke and Janussen 2013; Dayton et al. 2016). Interestingly, $R$. antarctica is the species best defined so far by molecular investigations (Vargas et al. 2017). Only small specimens of this species may be confused with small $R$. podagrosa, as Dayton et al. (2016) suspected. However, this is a general problem, as several Rossella species may look similar as juveniles, e.g., $R$. 
racovitzae, $R$. levis and $R$. fibulata (Göcke and Janussen 2013). An exact macroscopic species identification of juvenile Antarctic rossellids is thus hardly possible.

\section{Causes of morphological variability}

Besides macroscopic changes during growth from juveniles to adults, as discussed above, morphological variability, e.g., abnormal body shapes, may be due to asexual reproduction, which has been observed in several rossellid species, or larvae settling and growing on larger sponges. Teixidó et al. (2006) reported budding in 35\% of specimens of the " $R$. $n u d a$ type" in the eastern Weddell Sea. However, as their " $R$. nuda type" included an unknown proportion of $A$. joubini, they could not tell whether the budding pertains to either or both of the species. The smooth budding sponges we could clearly identify in our image material were all Rossella, i.e., we did not find any budding specimens of A. joubini. As budding has also not been reported elsewhere for A. joubini, despite studies lasting several decades (Dayton et al. 2013, 2016), we take this as a strong indication that A. joubini does not propagate by budding. Therefore, we suggest that the budding sponges investigated by Teixidó et al. (2006) were most likely $R$. nuda and not A. joubini. The budding Rossella still show the typical characteristics of the genus, despite variations in color and the number of buds. In lightbrown or pink specimens with particularly strong budding, the assignment to $R$. nuda or $R$. vanhoeffeni may be difficult. However, we often observed normal non-budding $R$. vanhoeffeni (brown) next to budding $R$. nuda (white, beige or pink; Fig. 7b, d).

Other changes in body shape reported as reproductive strategies include division and bipartition in $R$. nuda (e.g., Fig. $4 \mathrm{~g}$ ) and $R$. vanhoeffeni, bipartition and strangulation in $R$. racovitzae, and fragmentation in an unidentified hexactinellid (Teixidó et al. 2006). However, asexual reproduction seems to be rather rare in $R$. vanhoeffeni and $R$. racovitzae according to our observations and Teixidó et al. (2006). The budding attributed to R. racovitzae (e.g., Dayton 1979; Barthel and Gutt 1992; Barthel and Tendal 1994) does in fact refer to the species $R$. podagrosa, as discussed above. Thus, there are two species with extensive budding, $R$. podagrosa and $R$. nuda, which are clearly different in their macroscopic appearance.

It is not yet understood how environmental conditions, like currents or food availability, may affect macroscopic characteristics of Antarctic rossellid sponges. Adaptations of the sponge body to current strength and wave exposure have been reported for demosponges which develop a stiffer, more robust body morph in habitats with strong currents or waves (e.g., Palumbi 1986; McDonald et al. 2002). The strength of prevailing currents may possibly also affect the consistency of the body wall of Antarctic rossellids. Furthermore, environmental factors have been suggested to cause seasonal variations in surface structure and texture, as well as in spicule characteristics of a temperate demosponge species (Schönberg and Barthel 1998 and references therein).

Maldonado et al. (1999) showed that the spicule inventory in a Mediterranean demosponge may change tremendously with changing concentrations of silicic acid, the basis for spicule formation in many sponges and especially hexactinellids. Environmental effects on the spicule inventory have since been suggested by further studies (e.g., Cárdenas et al. 2011 and references therein). It cannot be ruled out that also in hexactinellids, spicule characteristics may not provide a conservative basis for species identification as commonly assumed. Göcke and Janussen (2013) observed unusually large spicule sizes in several Rossella species at one location in the eastern Weddell Sea and suggested locally high silicic acid concentrations as cause. Interestingly, despite the large spicule sizes, the body sizes of these sponges were normal or rather small. Thus, regional differences in silicic acid concentration, which varies between 100 and $160 \mu \mathrm{M}$ in Antarctic bottom waters (Tréguer et al. 1995), may cause some variability in the spicules of wide-spread species. This poses another challenge for taxonomic species identification and delimitation of closely related species. Therefore, the zoogeographic occurrence and environmental distinctions should be considered in species descriptions.

Temporal morphological variability has been observed in specimens of Caribbean giant barrel sponges, Xestospongia muta, which may change their surface from smooth to bumpy over the course of some years (J. Pawlik, pers. comm.). The reasons for this change are unknown, but it suggests the possibility that Antarctic rossellids might likewise be able to change the number and form of their conules over time. This would explain the high macroscopic variability in some species, especially $R$. racovitzae, and observations of specimens which do not fit the typical morphologies of the described species.

\section{Relevance and applicability of the described characteristics}

Several of the sponge species we discuss are known to have a circum-Antarctic distribution (Barthel and Tendal 1994; Janussen and Downey 2014). Furthermore, many characteristics we report for sponges in the Weddell Sea correspond to reports from the Ross Sea (e.g., Dayton et al. 2016). Thus, our macroscopic approach to the identification of these species can be applied throughout the entire Southern Ocean. This approach is especially relevant and timely, as the use of non-invasive imaging technology in marine research has increased over the last decades (Mallet and Pelletier 2014) and technologies as well as methodologies continue to develop rapidly (Durden et al. 2016; Schoening 
et al. 2017). In the Antarctic, in particular, they are already widely applied in benthic studies in the Weddell Sea (e.g., Fillinger et al. 2013; Segelken-Voigt et al. 2016; Ambroso et al. 2017), the East Antarctic shelf (e.g., Smith et al. 2015; Post et al. 2017), the Ross Sea (e.g., Clark and Bowden 2015), the West Antarctic (e.g., Eastman et al. 2013) and in large-scale comparative studies (e.g., Santagata et al. 2018).

The detectability of macroscopic characteristics depends on the quality of the image material. They may not be visible, if the resolution is low, the images are too dark, the distance from the camera is too high or the viewing angle is unfortunate. However, with modern technology and careful collection of image material, these problems should be avoidable. Even if only some of the described characteristics can be observed, they are still helpful indicators for in-situ identification.

The general body shape and the presence, form and size of conules and protruding spicules or a spicule veil allow a first rough classification or, in case of species with a unique habitus like $R$. fibulata, $R$. antarctica or $R$. podagrosa, even a confident identification. Distinguishing macroscopically similar species requires more attention to detail. The basal spicule tuft is usually an obvious feature and may be visible in situ even at lower image quality. It is not only characteristic in $R$. nuda and A. joubini, but also in $R$. vanhoeffeni (Schulze and Kirkpatrick 1910; Barthel and Tendal 1994) and R. levis (Barthel and Tendal 1994; Göcke and Janussen 2013). The structure of the outer surface, however, can only be seen in situ with very high resolution and from a very close distance or when zooming in (Fig. 4). It can usually be well examined in trawl-collected specimens and can thus be used to quickly sort individuals of $R$. nuda and A. joubini from trawls.

As sponges in general show high morphological plasticity (Gaino et al. 1995), examples of which have been discussed above, macroscopic characteristics should not be viewed as absolute criteria and species identification should not be based on any single characteristic alone. For confident insitu or image-based species identification, we recommend using a combination of as many characteristics as possible.

\section{Implications for future research}

The complicated taxonomic history of the genus Rossella necessitates a thorough revision of all species, including the type material (Tabachnick 2002). Due to previous synonymizations and revisions as in the case of $R$. podagrosa and $R$. racovitzae (Göcke et al. 2015), or uncertain identifications as in the case of $R$. nuda and A. joubini (Teixidó et al. 2006), older publications should be consulted cautiously and given species names treated with care. So far, only one systematic molecular study has been done on five species of Rossella to elucidate their taxonomic relation (Vargas et al.
2017). However, on the basis of the genetic markers used, Vargas et al. (2017) could only differentiate one species ( $R$. antarctica) from the rest, which they thus called a species flock. They further suggested that this scenario might reflect ongoing speciation processes within the genus. Therefore, a major task for future research on Antarctic rossellid sponges is to reconcile traditional taxonomy based on spicules (e.g., Barthel and Tendal 1994) with molecular taxonomy (e.g., Vargas et al. 2017) as well as in-situ approaches relying on external morphology (this study).

The ideal solution would be an integrated approach to sponge species identification encompassing (i) in-situ recordings by ROV or divers, (ii) collection of the recorded specimens, (iii) documentation of all macroscopic characteristics immediately after collection, (iv) microscopic study of the spicules, and (v) molecular genetic studies, all on the basis of the same individuals. Especially revisions of poorly described species, e.g., $R$. racovitzae and $R$. villosa, should combine the different approaches. Furthermore, several individuals of different size and age (juveniles as well as adults) should be included in species descriptions. The methods for sponge collection should be chosen carefully so that sponges are collected in a good state instead of being torn and loaded with sediment or contaminated with spicules of other species during collection. The better the state of collected sponges, the more use can be made of the material and the easier it is to relate to in-situ images.

In cases where precise in-situ species identification is difficult, we suggest not to lump sponges together, but to distinguish them based on repeatedly observed macroscopic characteristics. If distinct morphotypes are well described, they may be named properly in the future when we have acquired more knowledge about Rossella taxonomy. Furthermore, also in morphologically variable species like $R$. racovitzae it may be worthwhile to distinguish the different morphotypes, as they may be related to factors we do not yet understand (e.g., environmental conditions, age, nutritional or reproductive stage).

\section{Conclusion}

We show that the common rossellid sponge species of the Antarctic shelf have unique macroscopic characteristics by which they can be identified in situ without expert taxonomic knowledge. The smooth-walled species A. joubini, $R$. $n u d a$ and $R$. vanhoeffeni, previously often mixed up, can be reliably distinguished from each other by the form of their basal spicule tuft, their surface structure and their overall body form. The previously synonymized species $R$. racovit$z a e$ and $R$. podagrosa can easily be distinguished by their markedly different habitus. Based on our results, the oftmentioned ' $R$. racovitzae budding type' in older publications 
does in fact refer to $R$. podagrosa and this species is common not only in the Ross Sea, but also in the Weddell Sea.

We conclude that macroscopic characteristics are helpful means in distinguishing Antarctic rossellid sponge species. It is important in their identification and description to consider not only the spicules and molecular data, but the outer morphology, as well. In addition to the first comprehensive overview of macroscopic characteristics given here, a large number of in-situ and ex-situ images are available as reference through the data publisher PANGAEA (Federwisch et al. 2019).

\begin{abstract}
Acknowledgements Open Access funding provided by Projekt DEAL. We are indebted to the captains, crews and cruise leaders of Polarstern expeditions PS77, PS82 and PS96 for making this work possible. Many thanks go to the ROV pilots T. Lundälv (PS77), N. Owsianowski (PS82), R. Johansson and E. Andersson (PS96) and to the many people helping with the ROV deployments during these expeditions. We thank L. Fillinger and A. Kluibenschedl for their help with sponge collections and ROV deployments during PS77 and PS82, respectively, and M. Nalmpanti for helping with spicule preparations and identification of the PS82 sponges. We further thank P. Dayton, R. Downey, C. Göcke and D. Kersken for valuable discussions on Antarctic hexactinellid sponges. In addition, we thank P. Dayton and one anonymous reviewer for their constructive comments, which have helped to improve the manuscript. This work was funded through AWI's programs PACES I+ II (Topic 1 WP 6) and expedition grants AWI_PS82_03 and AWI_ PS96_02. DJ thanks Deutsche Forschungsgemeinschaft (DFG) for funding of Antarctic sponge research Projects JA-1063/13,1-2 and JA-1063/17-1.
\end{abstract}

\section{Compliance with ethical standards}

Conflict of interest The authors declare that they have no conflict of interest.

Open Access This article is licensed under a Creative Commons Attribution 4.0 International License, which permits use, sharing, adaptation, distribution and reproduction in any medium or format, as long as you give appropriate credit to the original author(s) and the source, provide a link to the Creative Commons licence, and indicate if changes were made. The images or other third party material in this article are included in the article's Creative Commons licence, unless indicated otherwise in a credit line to the material. If material is not included in the article's Creative Commons licence and your intended use is not permitted by statutory regulation or exceeds the permitted use, you will need to obtain permission directly from the copyright holder. To view a copy of this licence, visit http://creativecommons.org/licenses/by/4.0/.

\section{References}

Ambroso S, Salazar J, Zapata-Guardiola R, Federwisch L, Richter C, Gili JM, Teixidó N (2017) Pristine populations of habitat-forming gorgonian species on the Antarctic continental shelf. Sci Rep 7:12251. https://doi.org/10.1038/s41598-017-12427-y

Arndt JE, Schenke HW, Jakobsson M, Nitsche FO, Buys G, Goleby B, Rebesco M, Bohoyo F, Hong J, Black J, Greku R, Udintsev G, Barrios F, Reynoso-Peralta W, Taisei M, Wigley R (2013) The International Bathymetric Chart of the Southern Ocean (IBCSO)
Version 1.0 - A new bathymetric compilation covering circumAntarctic waters. Geophys Res Lett 40:3111-3117. https://doi. org/10.1002/grl.50413

Barthel D (1992) Do hexactinellids structure Antarctic sponge associations? Ophelia 36:111-118

Barthel D (1997) Fish eggs and pentacrinoids in Weddell Sea hexactinellids: further examples for the structuring role of sponges in Antarctic benthic ecosystems. Polar Biol 17:91-94. https://doi. org/10.1007/s003000050110

Barthel D, Gutt J (1992) Sponge associations in the eastern Weddell Sea. Antarct Sci 4:137-150. https://doi.org/10.1017/S095410209 2000221

Barthel D, Tendal OS (1994) Antarctic Hexactinellida. In: Wägele JW, Sieg J (eds) Synopses of the Antarctic Benthos, Vol. 6. Koeltz Scientific Books, Koenigstein

Boury-Esnault N, Rützler K (1997) Thesaurus of sponge morphology. Smithson Contrib Zool 596:1-55

Brueggeman P (2019) Underwater field guide to Ross Island \& McMurdo Sound, Antarctica. https://www.peterbrueggeman.com/ nsf/fguide/index.html. Accessed 7 June 2019

Burton M (1929) Porifera. Part II. Antarctic sponges. British Antarctic ('Terra Nova') Expedition, 1910. Natural History Report, London, British Museum (Natural History), Zoology 6(4):393-458, pls. $\mathrm{I}-\mathrm{V}$

Cárdenas P, Xavier JR, Reveillaud J, Schander C, Rapp HT (2011) Molecular phylogeny of the Astrophorida (Porifera, Demospongiae) reveals an unexpected high level of spicule homoplasy. PLoS ONE 6:e18318. https://doi.org/10.1371/journal.pone.0018318

Carter HJ (1872) On two new sponges from the Antarctic Sea, and on a new species of Tethya from Shetland; together with observations on the reproduction of sponges commencing from zygosis of the sponge animal. Ann Mag Nat Hist (4) 9(54):409-435, pls. $\mathrm{XX}-\mathrm{XXII}$

Clark MR, Bowden DA (2015) Seamount biodiversity: high variability both within and between seamounts in the Ross Sea region of Antarctica. Hydrobiologia 761:161-180. https://doi.org/10.1007/ s10750-015-2327-9

Dayton PK (1979) Observations of growth, dispersal and population dynamics of some sponges in McMurdo Sound, Antarctica. In: Levi C, Boury-Esnault $\mathrm{N}$ (eds) Colloques Internationaux du C.N.R.S. No. 291 - Biologie des spongiaires - Sponge Biology. Centre National de la Recherche Scientifique, Paris, pp 271-282

Dayton PK, Robilliard GA, Paine RT, Dayton LB (1974) Biological accommodation in the benthic community at McMurdo Sound, Antarctica. Ecol Monogr 44:105-128

Dayton PK, Kim S, Jarrell SC, Oliver JS, Hammerstrom K, Fisher JL, O'Connor K, Barber JS, Robilliard G, Barry J, Thurber AR, Conlan K (2013) Recruitment, growth and mortality of an Antarctic hexactinellid sponge Anoxycalyx joubini. PLoS ONE 8:e56939. https://doi.org/10.1371/journal.pone.0056939

Dayton PK, Jarrell SC, Kim S, Thrush S, Hammerstrom K, Slattery M, Parnell E (2016) Surprising episodic recruitment and growth of Antarctic sponges: implications for ecological resilience. J Exp Mar Biol Ecol 482:38-55. https://doi.org/10.1016/j.jembe .2016 .05 .001

Durden JM, Schoening T, Althaus F, Friedman A, Garcia R, Glover AG, Greinert J, Jacobsen Stout N, Jones DOB, Jordt A, Kaeli JW, Koser K, Kuhnz LA, Lindsey D, Morris KJ, Nattkemper TW, Osterloff J, Ruhl HA, Singh H, Tran M, Bett BJ (2016) Perspectives in visual imaging for marine biology and ecology: from acquisition to understanding. Oceanogr Mar Biol 54:1-72

Eastman JT, Amsler MO, Aronson RB, Thatje S, McClintock JB, Vos SC, Kaeli JW, Singh H, La Mesa M (2013) Photographic survey of benthos provides insights into the Antarctic fish fauna from the Marguerite Bay slope and the Amundsen Sea. Antarct Sci 25:31-43. https://doi.org/10.1017/S0954102012000697 
Federwisch L, Janussen D, Richter C (2019) Reference images for identification of common Antarctic glass sponges (Porifera: Hexactinellida: Rossellidae) based on macroscopic characteristics. Alfred Wegener Institute, Helmholtz Centre for Polar and Marine Research, Bremerhaven, PANGAEA. https://doi.org/10.1594/ PANGAEA.897623

Fillinger L, Janussen D, Lundälv T, Richter C (2013) Rapid glass sponge expansion after climate-induced Antarctic ice shelf collapse. Curr Biol 23:1330-1334. https://doi.org/10.1016/j. cub.2013.05.051

Gaino E, Manconi R, Pronzato R (1995) Organizational plasticity as a successful conservative tactics in sponges. Anim Biol 4:31-43

Gatti S (2002) The role of sponges in high-Antarctic carbon and silicon cycling - a modelling approach. Ber Polarforsch Meeresforsch 434:1-124. https://doi.org/10.2312/BzPM_0434_2002

Gerdes D, Klages M, Arntz WE, Herman RL, Galéron J, Hain S (1992) Quantitative investigations on macrobenthos communities of the southeastern Weddell Sea shelf based on multibox corer samples. Polar Biol 12:291-301

Göcke C, Janussen D (2011) ANT XXIV/2 (SYSTCO) Hexactinellida (Porifera) and bathymetric traits of Antarctic glass sponges (incorporating ANDEEP-material); including an emendation of the rediscovered genus Lonchiphora. Deep-Sea Res Pt II 58:20132021. https://doi.org/10.1016/j.dsr2.2011.01.006

Göcke C, Janussen D (2013) Hexactinellida of the genus Rossella, of ANT XXIV/2 (SYSTCO I) Expedition - Antarctic Eastern Weddell Sea. Zootaxa 3692:102-122

Göcke C, Janussen D, Reiswig HM, Jarrell SC, Dayton PK (2015) Rossella podagrosa Kirkpatrick, 1907 - A valid species after all. Zootaxa 4021:169-177. https://doi.org/10.11646/zoota xa.4021.1.7

Gutt J, Koltun VM (1995) Sponges of the Lazarev and Weddell Sea, Antarctica: explanations for their patchy occurrence. Antarct Sci 7:227-234. https://doi.org/10.1017/S0954102095000320

Gutt J, Böhmer A, Dimmler W (2013) Antarctic sponge spicule mats shape macrobenthic diversity and act as a silicon trap. Mar Ecol Prog Ser 480:57-71. https://doi.org/10.3354/meps10226

Gutt J, Cummings V, Dayton P, Isla E, Jentsch A, Schiaparelli S (2016) Antarctic marine animal forests: three-dimensional communities in Southern Ocean ecosystems. In: Rossi S, Bramanti L, Gori A, Orejas Saco del Valle C (eds) Marine Animal Forests, 1st edn. Springer, Cham. https://doi.org/10.1007/978-3-319-17001-5-8-1

Janussen D, Downey RV (2014) Chapter 5.5. Porifera. In: De Broyer C, Koubbi P, Griffiths HJ, Raymond B, d' Udekem d'Acoz C, et al. (eds) Biogeographic Atlas of the Southern Ocean, 1st edn. Scientific Committee on Antarctic Research, Cambridge, pp 94-102

Kersken D, Göcke C, Brandt A, Lejzerowicz F, Schwabe E, Seefeldt MA, Veit-Köhler G, Janussen D (2014) The infauna of three widely distributed sponge species (Hexactinellida and Demospongiae) from the deep Ekström Shelf in the Weddell Sea, Antarctica. Deep-Sea Res Pt II 108:101-112. https://doi.org/10.1016/j. dsr2.2014.06.005

Kersken D, Feldmeyer B, Janussen D (2016) Sponge communities of the Antarctic Peninsula: influence of environmental variables on species composition and richness. Polar Biol 39:851-862. https ://doi.org/10.1007/s00300-015-1875-9

Kirkpatrick R (1907) Porifera Hexactinellida. National Antarctic Expedition (S.S. 'Discovery') 1901-1904. Nat Hist 3:1-25, pls 1-7

Knust R, Schröder M (2014) The Expedition PS82 of the Research Vessel POLARSTERN to the southern Weddell Sea in 2013/2014. Ber Polarforsch Meeresforsch 680:1-155. https://doi.org/10.2312/ BzPM_0680_2014

Knust R, Gerdes D, Mintenbeck K (2012) The expedition of the research vessel "Polarstern" to the Antarctic in 2011 (ANTXXVII/3) (CAMBIO). Ber Polarforsch Meeresforsch 644:1-202. https://doi.org/10.2312/BzPM_0644_2012
Koltun VM (1976) Porifera-Part 1: Antarctic Sponges. Report B.A.N.Z. Antarctic Research Expedition 1929-1931 (B, Zoology and Botany) 5(4):153-198, pls. 1-3

Kunzmann K (1996) Associated fauna of selected sponges (Hexactinellida and Demospongiae) from the Weddell Sea, Antarctica. Ber Polarforsch 210:1-93. https://doi.org/10.2312/BzP_0210_1996

Maldonado M, Carmona MC, Uriz MJ, Cruzado A (1999) Decline in Mesozoic reef-building sponges explained by silicon limitation. Nature 401:785-788

Maldonado M, Aguilar R, Bannister RJ, Bell JJ, Conway KW, Dayton PK, Díaz C, Gutt J, Kelly M, Kenchington ELR, Leys SP, Pomponi SA, Rapp HT, Rützler K, Tendal OS, Vacelet J, Young CM (2016) Sponge grounds as key marine habitats: a synthetic review of types, structure, functional roles, and conservation concerns. In: Rossi S, Bramanti L, Gori A, Orejas Saco del Valle C (eds) Marine animal forests, 1st edn. Springer, Cham. https://doi. org/10.1007/978-3-319-17001-5-24-1

Mallet D, Pelletier D (2014) Underwater video techniques for observing coastal marine biodiversity: a review of sixty years of publications (1952-2012). Fish Res 154:44-62. https://doi.org/10.1016/j. fishres.2014.01.019

McDonald JI, Hooper JNA, McGuinness KA (2002) Environmentally influenced variability in the morphology of Cinachyrella australiensis (Carter 1886) (Porifera: Spirophorida: Tetillidae). Mar Freshw Res 53:79-84. https://doi.org/10.1071/MF00153

Palumbi SR (1986) How body plans limit acclimation: responses of a demosponge to wave force. Ecology 67:208-214

Post AL, Lavoie C, Domack EW, Leventer A, Shevenell A, Fraser AD (2017) Environmental drivers of benthic communities and habitat heterogeneity on an East Antarctic shelf. Antarct Sci 29:17-32. https://doi.org/10.1017/S0954102016000468

Reiswig HM (1990) Correction of Ijima's (1927) list of recent hexactinellid sponges (Porifera). P Biol Soc Wash 103:731-745

Santagata S, Ade V, Mahon AR, Wisocki PA, Halanych KM (2018) Compositional differences in the habitat-forming bryozoan communities of the Antarctic shelf. Front Ecol Evol 6:116. https://doi. org/10.3389/fevo.2018.00116

Schoening T, Durden JM, Preuss I, Albu AB, Purser A, De Smet B, Dominguez-Carrió C, Yesson C, de Jonge D, Lindsay D, Schulz J, Möller KO, Beisiegel K, Kuhnz L, Hoeberechts M, Piechaud N, Sharuga S, Treibitz T (2017) Report on the marine imaging workshop 2017. Res Ideas Outcomes 3:e13820. https://doi. org/10.3897/rio.3.e13820

Schönberg CHL, Barthel D (1998) Unreliability of demosponge skeletal characters: the example of Halichondria panicea. In: Watanabe Y, Fusetani N (eds) Sponge sciences: multidisciplinary perspectives. Springer, Tokyo, pp 41-53

Schröder M (2016) The expedition PS96 of the research vessel POLARSTERN to the southern Weddell Sea in 2015/2016. Ber Polarforsch Meeresforsch 700:1-142. https://doi.org/10.2312/ BzPM_0700_2016

Schulze FE, Kirkpatrick R (1910) Die Hexactinelliden der Deutschen Südpolar-Expedition 1901-1903. Deutsche Südpolar-Expedition 1901-1903, XII. Band, Zoologie IV. Band (1): 1-62, pls I-X

Segelken-Voigt A, Bracher A, Dorschel B, Gutt J, Huneke W, Link H, Piepenburg D (2016) Spatial distribution patterns of ascidians (Ascidiacea: Tunicata) on the continental shelves off the northern Antarctic Peninsula. Polar Biol 39:863-879. https://doi. org/10.1007/s00300-016-1909-y

Smith J, O'Brien PE, Stark JS, Johnstone GJ, Riddle MJ (2015) Integrating multibeam sonar and underwater video data to map benthic habitats in an East Antarctic nearshore environment. Estuar Coast Shelf Sci 164:520-536. https://doi.org/10.1016/j. ecss.2015.07.036

Tabachnick KR (2002) Family Rossellidae Schulze, 1885. In: Hooper JNA, van Soest RWM (eds) Systema Porifera. A guide to the 
classification of sponges, Vol. 2. Kluwer Academic/Plenum Publishers, New York, pp 1441-1505

Teixidó N, Gili JM, Uriz MJ, Gutt J, Arntz WE (2006) Observations of asexual reproductive strategies in Antarctic hexactinellid sponges from ROV video records. Deep-Sea Res Pt II 53:972-984. https:// doi.org/10.1016/j.dsr2.2006.02.008

Topsent E (1901) Spongiaires. Résultats du voyage du S.Y. 'Belgica' en 1897-99 sous le commandement de A. de Gerlache de Gomery. Expédition antarctique belge. Zoologie 4:1-54, pls I-VI

Topsent E (1916) Diagnoses d'éponges recueillies dans l'Antarctique par le Pourquoi-Pas? Bull Mus natl d'Hist nat (1) 22(3):163-172

Tréguer P, Nelson DM, Van Bennekom AJ, DeMaster DJ, Leynaert A, Quéguiner B (1995) The silica balance in the world ocean: a reestimate. Science 268:375-379. https://doi.org/10.1126/scien ce.268.5209.375

Vargas S, Dohrmann M, Göcke C, Janussen D, Wörheide G (2017) Nuclear and mitochondrial phylogeny of Rossella (Hexactinellida: Lyssacinosida, Rossellidae): a species and a species flock in the Southern Ocean. Polar Biol 40:2435-2444. https://doi. org/10.1007/s00300-017-2155-7

Publisher's Note Springer Nature remains neutral with regard to jurisdictional claims in published maps and institutional affiliations. 